\title{
Microbial impact of the pesticide chlorpyrifos on Swedish and Italian biobeds
}

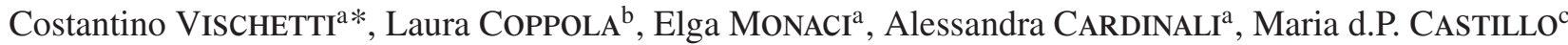 \\ a Dipartimento di Scienze Ambientali e delle Produzioni Vegetali, Università Politecnica delle Marche, Via Brecce Bianche, 60131 Ancona, Italy \\ ${ }^{b}$ Dipartimento di Scienze dei Sistemi Colturali, Forestali e dell' Ambiente, Università della Basilicata, Potenza, Italy \\ ${ }^{\mathrm{c}}$ Department of Microbiology, Swedish University of Agricultural Sciences, Uppsala, Sweden
}

(Accepted 16 March 2007)

\begin{abstract}
Biobeds provide a simple and cheap solution to reducing point-source contamination by pesticides from farm activities. In its original design, the Swedish biobed is a clay-lined pit in the ground filled with a biomixture of topsoil, peat and straw and covered with a grass layer. The straw stimulates the growth of lignin-degrading fungi and the formation and activity of ligninolytic enzymes which can degrade many different pesticides. Here we compared the behaviour of the chlorpyrifos pesticide in two biobeds of different composition: a Swedish biobed composed of $50 \% \mathrm{v}$ vine straw, $25 \% \mathrm{v}$ peat and $25 \% \mathrm{v}$ Swedish soil; and an Italian biobed composed of $40 \% \mathrm{v}$ vine straw, $40 \% \mathrm{v}$ green compost and $20 \%$ v Italian soil. Microbial biomass was measured in the Italian biomix by the fumigation-extraction method. The microbial activity was estimated by measuring mineralisation of a synthetic lignin, ${ }^{14} \mathrm{C}$-de-hydrogenative polymerisate $\left({ }^{14} \mathrm{C}\right.$-DHP) in the Swedish biomix. Microbial respiration was followed over time in both biomixes. Our results show that the chlorpyrifos half-lives were similar in both biomixes. The microbial biomass content was reduced by 25 and $50 \%$ with, respectively, 10 and $50 \mathrm{mg} \mathrm{kg}^{-1}$ chlorpyrifos in the Italian biomix. The respiration activity was affected only at $50 \mathrm{mg} \mathrm{kg}{ }^{-1}$ chlorpyrifos in the Italian biomix. No effect was observed in the Swedish biomix despite the higher chlorpyrifos concentration of $100 \mathrm{mg} \mathrm{kg}^{-1}$. The mineralisation of ${ }^{14} \mathrm{C}$-DHP was not affected by the presence of chlorpyrifos in the Swedish biomix. These findings could be explained by the presence of chlorpyrifos-sensitive microorganisms in the Italian biomix and chlorpyrifosresitant microorganisms in the Swedish biomix. The more robust microflora developed in the Swedish biomix may be explained by its lower nitrogen content, higher $\mathrm{C} / \mathrm{N}$ ratio and lower $\mathrm{pH}$, all of which are favourable for the development of lignin-degrading fungi and their activity. In Sweden more than 1000 biobeds are in practical use on farms and they have been shown to be efficient at reducing pesticide water-body contamination. The present study compares the capability of an Italian biomix for degrading pesticides to that shown by the Swedish original biomix in order to introduce this biological system for a sustainable Italian agriculture.
\end{abstract}

chlorpyrifos / organic biomixes / pesticide biodegradation / ligninolytic microflora

\section{INTRODUCTION}

The environment can be adversely impacted by pesticides that originate from diffuse or point sources in agricultural practices. Diffuse sources relate to the movement of pesticides through mechanisms such as spray drift, runoff and leaching (Accinelli et al., 2005; Screpanti et al., 2005). Point sources include any contamination derived from activities such as tank filling, washing and waste disposal, spillages and leaks from faulty equipment (Carter, 2000).

The use of biobeds is a simple and cheap solution to reducing point-source contamination of pesticides from farm activities such as filling of spraying equipment (Torstensson, 2000). A typical biobed is shown in Photo 1 . In its original design, the biobed is a clay-lined pit in the ground filled with a biomixture of topsoil, peat and straw (25:25:50 percent by volume) and covered with a grass layer (Torstensson and Castillo, 1997). The straw stimulates the growth of lignin-degrading fungi and the formation and activity of ligninolytic enzymes, such as manganese and lignin peroxidases, which can degrade

*Corresponding author: c.vischetti@univpm.it

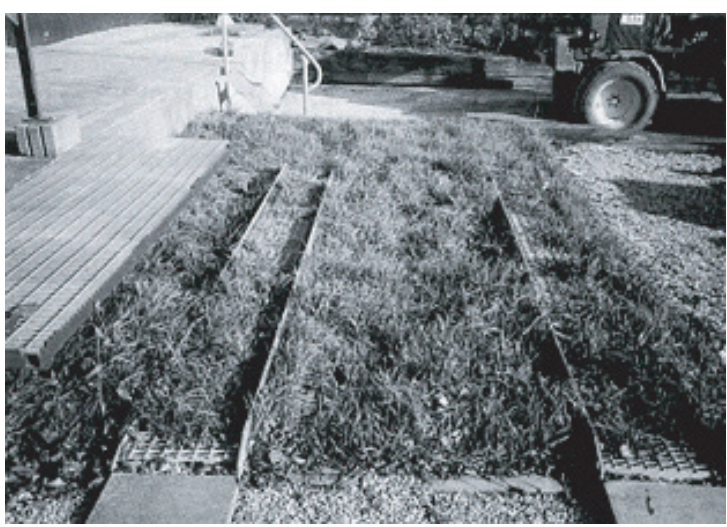

Photo 1. A typical biobed system consisting of a 60-cm-deep pit filled with a mixture of chopped straw, peat mould and topsoil; grass layer and drawing ramps on the surface.

many different pesticides (Castillo et al., 1997, 2000, 2001; von Wirén-Lehr et al., 2001). The peat gives sorption capacity and helps to keep the humidity. The soil also contributes, with 
sorption capacity and with other pesticide-degrading microorganisms. Many authors have reported the efficiency of biobeds at reducing pesticide concentration in discharge and washing water (Fait et al., 2007; Rose et al., 2003).

In order to adapt this biological system to Italian operative conditions there is a need to find locally available organic materials that can function in the same effective way as is obtained from the original Swedish recipe. Under Mediterranean conditions, peat is not easily available and economical to use. Therefore, there is the need to find an organic material that can substitute the peat by providing a high sorption capacity and keeping an appropriate humidity in the biobed. A further advantage would be if the substitute is also a source of microorganisms with pesticide catabolic activity. High-quality compost from garden residues and municipal wastes contains numerous and different active microorganisms and has shown a good retention capacity of pesticides (Vischetti et al., 2006). Previous studies have demonstrated the adsorption and degradation capability of some organic substrates against pesticides in Italian experimental conditions and a mixture of soil, vine branches and urban waste/garden compost was shown to be suitable for use in vineyards (Fait et al., 2004; Vischetti et al., 2004).

A major property of a biobed mixture is that it should promote a robust microbial flora with an efficient and durable pesticide degradation capacity. One concern when changing the original biobed composition, therefore, is an impaired functioning of the biobed that could lead to slow pesticide degradation and metabolite accumulation, which in turn could have toxic effects on the microbial amount and activity.

The broad-spectrum insecticide chlorpyrifos [O,O-diethyl $O$-(3,5,6-trichloro-2-pyridyl) phosphorothioate] is widely used in Italian agriculture. However, its toxicity against microorganisms (Martinez-Toledo et al., 1992) is of concern for the biobed function, as is also its major degradation product 3,5,6-trichloro-2-pyridinol (TCP), which can inhibit the microbial degradation of several pesticides (Racke et al., 1988).

The objectives of this work were to assess the microbial function and the effect of chlorpyrifos as a model substance in biomixes according to an Italian and the Swedish original composition. Microbial biomass was measured in the Italian biomix by the fumigation-extraction method (Sparling and West, 1988). The microbial activity was estimated by measuring mineralisation of a synthetic lignin ${ }^{14} \mathrm{C}$-DHP $\left({ }^{14} \mathrm{C}\right.$-DeHydrogenative Polymerisate) in the Swedish biomix. Microbial respiration was followed over time in both biomixes.

\section{MATERIALS AND METHODS}

\subsection{Chemicals}

Chlorpyrifos [O,O-diethyl $O$-(3,5,6-trichloro-2-pyridinyl) phosphorothioate] and TCP (3,5,6-trichloro-2-pyridinol) were supplied by Sigma Aldrich, Sweden AB. Both chemicals had 99\% purity. The synthetic lignin $\left({ }^{14} \mathrm{C}-\mathrm{DHP}-{ }^{14} \mathrm{C}\right.$-DeHydrogenative Polymerisate) was a gift from Paul Ander, Department of Wood Ultrastructure Research Centre, Swedish
University of Agricultural Sciences, and had a specific activity of $4.26 \mu \mathrm{Ci} / \mathrm{mg}$. Insta-Gel Plus was provided by Perkin Elmer, USA. All the other chemicals used in the experiment were supplied by VWR International AB.

\subsection{Substrates}

The urban waste/garden compost came from the GESENU plant in Pietramelina, Perugia, Italy. The straw from vine branches and the Italian soil came from the experimental field of the Università Politecnica delle Marche, Ancona, Italy. The Italian soil was a topsoil containing $37 \%$ clay and $1 \%$ organic carbon, pH 8.2. The Swedish soil, collected in Uppsala, Sweden, was an agricultural topsoil containing $14 \%$ clay and $1.0 \%$ organic carbon on a weight basis, $\mathrm{pH}$ 6.6. The Sphagnum peat mould came from Econova Garden $\mathrm{AB}$, Sweden. The soils were sieved $(2 \mathrm{~mm})$ and stored at $4{ }^{\circ} \mathrm{C}$ until used.

The Swedish biomix was composed of straw (vine branches), peat and Swedish soil in a proportion of 50-25-25 percent of volume. The Italian biomix comprised straw (vine branches), urban/garden compost and Italian soil in a proportion of 40-40-20 percent of volume. The biomixes were kept at $60 \%$ of the water-holding capacity. All the organic materials and soils were 2-mm sieved prior to mixing. The main characteristics of the biomixes and the soils tested in this study are reported in Table I.

\subsection{Microbial biomass carbon content and respiration with and without chlorpyrifos in the Italian biomix}

One $\mathrm{kg}$ of the Italian biomix was spiked with 10 or $50 \mathrm{mg} \mathrm{kg}^{-1}$ chlorpyrifos. The insecticide was added as a methanol solution to a 50-g biomix sub-sample. The methanol was allowed to evaporate and the sub-sample mixed back into the remaining biomixture. A control biomixture with no addition of chlorpyrifos was also run. The sample was adjusted to $60 \%$ WHC and incubated at $22{ }^{\circ} \mathrm{C}$ in the dark for 65 days. Periodically, triplicate samples ( $41 \mathrm{~g}$ ) were taken for measurement of chlorpyrifos concentration $(40 \mathrm{~g})$ and of microbial biomass carbon content $(1 \mathrm{~g})$ with the fumigation-extraction method described by Sparling and West (1988), slightly modified to adapt the method to the compost material. For respiration measurements, triplicate samples of the Italian biomix $(5 \mathrm{~g})$ were weighed into $100-\mathrm{mL}$ plastic flasks, spiked with 10 or $50 \mathrm{mg} \mathrm{kg}^{-1}$ chlorpyrifos, and the respiration measured as explained below.

\subsection{Respiration and mineralisation of ${ }^{14} \mathrm{C}$-DHP-lignin with and without chlorpyrifos in the Swedish biobed mixture}

Respiration and mineralisation of ${ }^{14} \mathrm{C}$-DHP-lignin was followed over time in the Swedish biobed mixture and in the Swedish soil in the presence and absence of chlorpyrifos. Triplicates of each sample ( $2 \mathrm{~g}$ Swedish biomix, $2 \mathrm{~g}$ Swedish 
Table I. Chemical properties of the materials used in the study.

\begin{tabular}{lccccc}
\hline Materials & $\begin{array}{c}\text { Composition } \\
\text { (\% of volume) }\end{array}$ & $\mathrm{pH}$ & $\begin{array}{c}\mathrm{C} \\
\text { (\% of weight) }\end{array}$ & $\begin{array}{c}\mathrm{N} / \mathrm{N} \\
\end{array}$ \\
\hline Italian biomix (straw-urban/garden-compost-Italian soil) & $40 / 40 / 20$ & 7.6 & 26.6 & 2 & 13.3 \\
Swedish biomix (straw-peat-Swedish soil) & $50 / 25 / 25$ & 5.7 & 18 & 0.35 & 51.4 \\
Italian soil & - & 8.2 & 1.0 & 0.33 & 3.0 \\
Swedish soil & - & 6.8 & 1.0 & 0.11 & 9.1 \\
\hline
\end{tabular}

soil) were weighed into 100 -mL plastic jars. The ${ }^{14} \mathrm{C}$-DHP (45 $000 \mathrm{dpm}$ ) was added into samples with and without chlorpyrifos $\left(100 \mathrm{mg} \mathrm{kg}^{-1}\right)$. The spiking was done according to Brinch et al. (2002) by treating a sub-sample (25\%) with the chemicals, mixing thoroughly and allowing the solvent to evaporate and finally mixing again with the remainder of the sample. The water content was kept at $60 \%$ of the waterholding capacity.

The plastic jars were installed in airtight glass jars together with two scintillation vials containing $\mathrm{NaOH}(0.2 \mathrm{M} ; 4 \mathrm{~mL})$ to trap carbon dioxide. The glass jars were incubated in the dark at $20^{\circ} \mathrm{C}$, water was added when necessary to maintain the designated moisture, and the $\mathrm{NaOH}$ solution was periodically removed and mineralisation and respiration were measured. The samples were incubated for 62 days in the dark at $20^{\circ} \mathrm{C}$. The chlorpyrifos concentration was measured at the beginning and at the end of the incubation period.

Collected ${ }^{14} \mathrm{CO}_{2}$ from the mineralisation of ${ }^{14} \mathrm{C}$-DHPlignin was measured in a liquid scintillation counter (Beckham LS 600 series, USA) after mixing with $4 \mathrm{~mL}$ Insta-Gel Plus. The mineralisation rate was expressed as accumulated ${ }^{14} \mathrm{CO}_{2}$ as a percentage of the initial radioactivity. In the respiration tests, the $\mathrm{CO}_{2}$ captured in the $\mathrm{NaOH}$ solution was determined by titrating the remaining alkali with $0.1 \mathrm{M} \mathrm{HCl}$ after precipitation of the carbonate with $0.1 \mathrm{M} \mathrm{BaCl}_{2}$. TIM 850 Titration Manager equipment (Radiometer Analytical, Copenhagen, Denmark) was used for the titrations. The respiration was expressed as accumulated $\mathrm{mg} \mathrm{CO}_{2} \mathrm{~g} \mathrm{sample}^{-1}$.

\subsection{Chlorpyrifos determination}

Chlorpyrifos was determined by extracting the samples vigorously overnight with $6 \mathrm{~mL}$ of acidified acetone per gram of substrates (acetone-water-concentrated phosphoric acid $98 / 1 / 1 \mathrm{v} / \mathrm{v}$ ) on a shaking table. Samples were centrifuged at $358 \times g$ and the solution was collected. The operation of extraction was repeated twice for $30 \mathrm{~min}$.

One $\mathrm{mL}$ of the pooled extract was centrifuged at $5411 \times g$ for $15 \mathrm{~min}$, and $0.5 \mathrm{~mL}$ of the solution was collected, diluted 1:1 with water and analysed by high-performance liquid chromatography (HPLC).

The HPLC analysis was performed using an Agilent 1100 series chromatograph, equipped with a variable wavelength UV detector (wavelength $300 \mathrm{~nm}$ ) and a Zorbax SB- C18 column, $5 \mu \mathrm{m} 4.6 \times 150 \mathrm{~mm}$, using a mobile phase of $50 \%$ $\mathrm{CH}_{3} \mathrm{CN}$ and $50 \%$ water/acetic acid $(95.3 / 4.7 ; \mathrm{v} / \mathrm{v})$ with a flow rate of $1.5 \mathrm{~mL} / \mathrm{min}$; under these conditions retention time was $10.7 \mathrm{~min}$ and recoveries were always higher than $60 \%$ for
Table II. Chlorpyrifos half-life at different initial concentrations in the various treatments.

\begin{tabular}{ccc}
\hline Treatment & $\mathrm{t}_{1 / 2}$ & $\mathrm{r}^{2 * * *}$ \\
\hline Swedish biomix and chlorpyrifos $100 \mathrm{mg} \mathrm{kg}^{-1}$ & 47 & - \\
Italian biomix and chlorpyrifos $50 \mathrm{mg} \mathrm{kg}^{-1}$ & 56 & $0.988^{* * *}$ \\
Italian biomix and chlorpyrifos $10 \mathrm{mg} \mathrm{kg}^{-1}$ & 43 & $0.991^{* * *}$ \\
Swedish soil and chlorpyrifos $100 \mathrm{mg} \mathrm{kg}^{-1}$ & 51 & - \\
Italian soil and chlorpyrifos $100 \mathrm{mg} \mathrm{kg}^{-1}$ & 84 & $0.989^{* * *}$ \\
\hline
\end{tabular}

*** Significant at $P<0.01$.

chlorpyrifos in the biomixes and higher than $80 \%$ for chlorpyrifos in soils.

\section{RESULTS AND DISCUSSION}

\subsection{Chlorpyrifos dissipation rate in Italian and Swedish biomixes and soils}

The half-life values of chlorpyrifos dissipation in the biomixes and the soils are shown in Table II, calculated by assuming first-order kinetics in the Italian experiment, and \% of dissipation per day in the Swedish experiment. The Italian biomixes gave half-lives of 43 and 56 days for initial chlorpyrifos concentrations of 10 and $50 \mathrm{mg} \mathrm{kg}^{-1}$, respectively. The half-life in the Swedish biomix was 47 days despite the higher initial concentration $\left(100 \mathrm{mg} \mathrm{kg}^{-1}\right)$ and the lower $\mathrm{pH}$. However, it thus seems that the degradation of chlorpyrifos is not significantly affected in the Italian biomix as compared with the Swedish one.

An indirect way of assessing accumulation of toxic metabolites can be to measure microbial biomass and activity. The effect of chlorpyrifos on the microbial respiration of both biomixes appears in Figure 1. The Swedish biomix had a respiration activity two-fold higher than the Italian one. This does not agree with our earlier results (data not shown), which showed that the Italian biomixes containing compost material instead of peat had higher respiration rates compared with a typical Swedish biomix. A possible explanation is that the compost used in this trial might have been more mature and hence had less available carbon sources.

Nevertheless, the presence of chlorpyrifos $\left(100 \mathrm{mg} \mathrm{kg}^{-1}\right)$ did not alter the respiration in the Swedish biomix (Fig. 1b) compared with the unamended control (Fig. 1a). In the Italian biomix no change in the respiration was observed at $10 \mathrm{mg} \mathrm{kg}^{-1}$ chlorpyrifos (Fig. 1d) but the respiration was lower 
$\mathrm{mg} \mathrm{CO} \mathrm{g}^{-1} \mathrm{~d} . \mathrm{m}$.
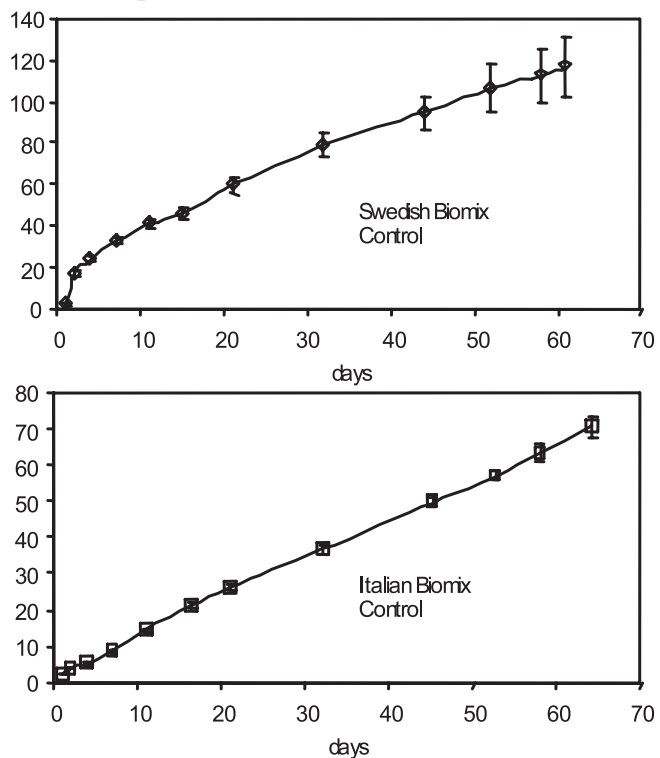
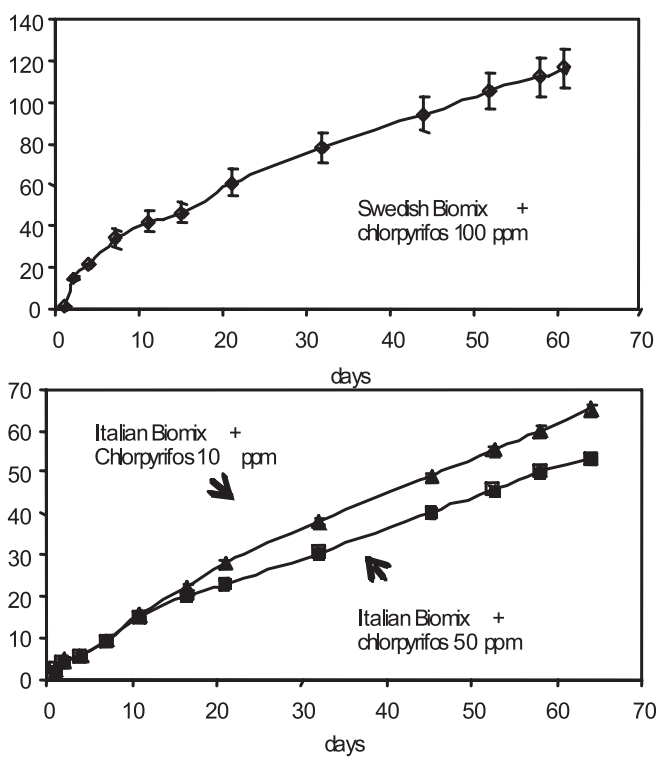

Figure 1. Respiration activity, expressed as $\mathrm{mg} \mathrm{CO}_{2} \mathrm{~g}^{-1}$ dry matter, was unaffected in the Swedish biomix with the addition of 100 ppm, while a significant decrease in activity was already observed in the Italian biomix at $50 \mathrm{ppm}$.

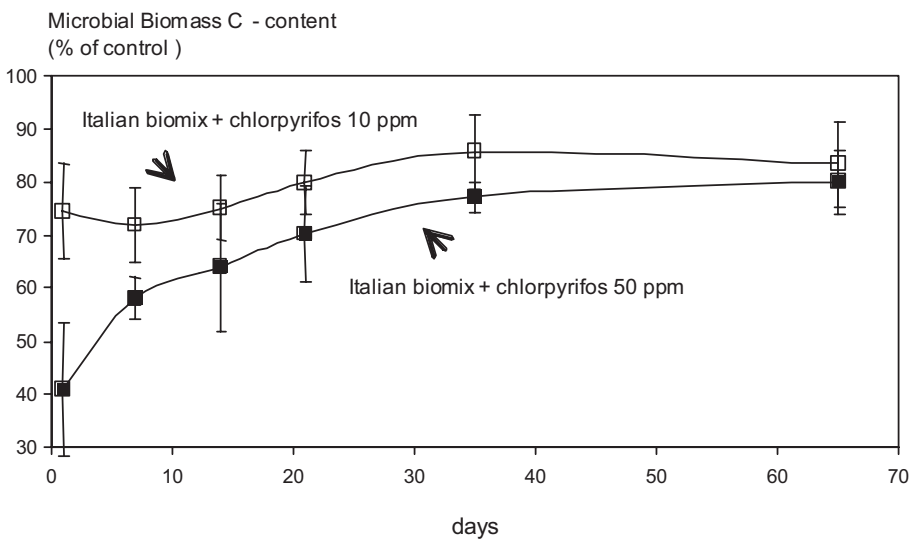

Figure 2. Decrease in the microbial biomass carbon content, expressed as percentage of the control, in the Italian biomix following chlorpyrifos addition.

in the biomix treated with $50 \mathrm{mg} \mathrm{kg}^{-1}$ chlorpyrifos (Fig. 1d) as compared with the control (Fig. 1c).

Moreover, the presence of chlorpyrifos in the Italian biomix had an effect on the amount of microbial biomass (Fig. 2), which was already reduced by 25 and $60 \%$ one day after the addition of chlorpyrifos at 10 and at $50 \mathrm{mg} \mathrm{kg}^{-1}$, respectively. Considering the half-lives obtained (43 and 56 days) for chlorpyrifos degradation, it thus seems chlorpyrifos itself is toxic to the microorganisms since only small amounts of metabolites would have been formed after one day only. Later, and probably due to chlorpyrifos dissipation, a slight recovery was observed, but the biomass did not completely recover during the 62 days of the incubation ( $\sim 80 \%$ of the control), probably due to continuous formation and degradation of toxic metabolites, e.g. 3,5,6-trichloro-2-pyridinol (TCP). Hence, the lower respiration activity in the $50 \mathrm{mg} \mathrm{kg}^{-1}$ chlorpyrifos treatment discussed previously might have been due to a smaller microbial biomass as compared with the control.

The straw in the biomix is crucial for the degradation of many pesticides in a biobed since it stimulates growth of fungi that produce peroxidases for lignin degradation (Torstensson and Castillo, 1997), which also efficiently degrade many pesticides (Castillo et al., 2001; Torstensson and Castillo, 1997; von Wirén-Lehr et al., 2001) as well as chlorophenols (Laine and Jorgensen, 1996) such as TCP. Due to the importance of the lignin-degrading microflora we assessed the mineralisation of a synthetic lignin, ${ }^{14} \mathrm{C}$-de-hydrogenative polymerisate $\left({ }^{14} \mathrm{C}\right.$-DHP), in the presence and absence of chlorpyrifos in the Swedish biomix. The Swedish soil alone was run as control. The ${ }^{14} \mathrm{C}$-DHP mineralisation was not affected by the presence of chlorpyrifos in the Swedish biomix (Fig. 3). Approximately $8 \%$ of the ${ }^{14} \mathrm{C}$-DHP was mineralised in 62 days in the 

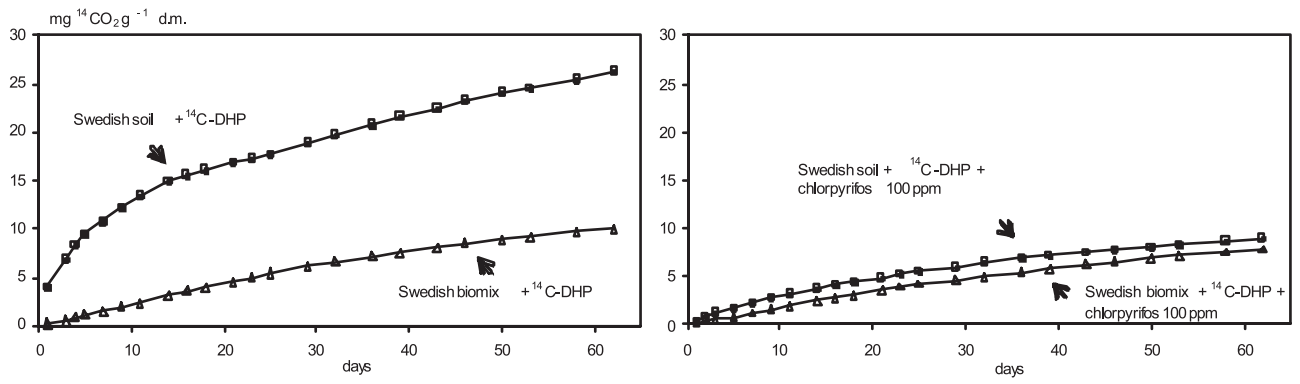

Figure 3. Mineralisation of ${ }^{14} \mathrm{C}$-DHP, expressed as percentage of the initial added ${ }^{14} \mathrm{C}$-DHP, was negatively affected by chlorpyrifos addition. DHP: ${ }^{14} \mathrm{C}$-de-hydrogenative polymerisate.

presence and absence of the insecticide. However, the Swedish soil in the absence of chlorpyrifos mineralised almost $26 \%$ of the ${ }^{14} \mathrm{C}$-DHP and only $9 \%$ in the presence of the insecticide. This particular soil also has an exceptional ability to degrade even high-molecular weight polyaromatic hydrocarbons (Pizzul et al., 2006a, b) which also might explain its high activity towards ${ }^{14} \mathrm{C}$-DHP. Thus, it seems that the mineralisation of ${ }^{14} \mathrm{C}$-DHP in the soil might be performed by chlorpyrifosresistant and chlorpyrifos-sensitive microorganisms.

To achieve a robust lignin-degrading microflora in a biomix, favourable conditions for efficient microorganisms and their degrading enzymes must be provided. The concentration of nitrogen in the Italian biomix $(2 \%)$ is much higher than in the Swedish one $(0.33 \%)$, which in turn contributes to a smaller $\mathrm{C} / \mathrm{N}$ ratio. To be ligninolytically efficient, lignin-degrading fungi often require low nitrogen contents and high $\mathrm{C} / \mathrm{N}$ ratios (the $\mathrm{C} / \mathrm{N}$ ratio in woody tissues can be higher than 350 ) (Deacon, 1983). Moreover, the lower $\mathrm{pH}$ in the Swedish (5.7) biomix as compared with the Italian one (7.6) would also stimulate the ligninolytic activity.

In summary, several results and physical/chemical properties show that the Swedish biomix more efficiently provides conditions leading to a more robust and efficient pesticidedegrading microflora compared with the Italian one: (a) the chlorpyrifos half-life in the Swedish biomix was not different from those in the Italian one, despite the higher initial chlorpyrifos concentration; (b) the respiration activity in the Swedish biomix was not negatively affected by the presence of chlorpyrifos as it was in the Italian biomix, despite the higher chlorpyrifos concentration used in the Swedish biomix; (c) the microbial biomass content was affected by the presence of chlorpyrifos in the Italian biomix and lower levels, compared with the unamended control, were observed during the whole incubation period; (d) the mineralisation of ${ }^{14} \mathrm{C}-\mathrm{DHP}$ was not affected by the presence of chlorpyrifos in the Swedish biomix; and (e) the Swedish biomix has a low nitrogen content, high $\mathrm{C} / \mathrm{N}$ ratio and low $\mathrm{pH}$, which are more suitable for lignin-degrading fungi and their activity.

\section{CONCLUSION}

For a mixture for biobeds in Italian conditions, one should consider composts with a high lignin content such as gar- den compost and soil which has developed a capacity to degrade pesticides through repeated amendments with straw. The Italian biomix was shown to be as effective as the Swedish biomix at chlorpyrifos degradation, but the presence of a more sensitive microflora demonstrated the necessity to enrich the Italian biomix with a suitable growing substrate to encourage the development of more active degrading microorganisms. The results obtained encourage water bodies' bio-prophylaxis through the adaptation of biobeds to sustain a low environmental impact in Italian operative conditions.

Acknowledgements: The authors wish to thank the Regione Marche Dipartimento Programmazione e Bilancio - Ancona, Italy, for financial support of this research.

\section{REFERENCES}

Accinelli C., Screpanti C., Vicari A. (2005) Influence of flooding on the degradation of linuron, isoproturon and metolachlor in soil, Agron. Sustain. Dev. 25, 401-406.

Brinch U.C., Ekelund F., Jacobsen C.S. (2002) Method for spiking soil samples with organic compounds, Appl. Environ. Microb. 68, $1808-1816$.

Carter A.D. (2000) How pesticides get into water and proposed reduction measures, Pestic. Outlook 11, 149-157.

Castillo M.d.P., Ander P., Stenström J. (1997) Lignin and manganese peroxidase activity in extracts from straw solid substrate fermentations, Biotechnol. Tech. 11, 701-706.

Castillo M.d.P., Ander P., Stenström J., Torstensson L. (2000) Degradation of the herbicide bentazon as related to enzyme production by Phanerochaete chrysosporium in a solid substrate fermentation system, World J. Microb. Biot. 16, 289-295.

Castillo M.d.P., von Wirén-Lehr S., Scheunert I., Torstensson L. (2001) Degradation of isoproturon by the white rot fungus Phanerochaete chrysosporium, Biol. Fert. Soils 33, 521-528.

Deacon J.W. (1983) Introduction to Modern Mycology, in: Wilkinson J.F. (Ed.), Basic Microbiology, Vol. 7, second ed., Blackwell Scientific Publication, Oxford, p. 239.

Fait G., Nicelli M., Trevisan M., Capri E. (2004) A biological system of decontamination of water polluted with pesticides on farms, Inform. Agrar. 60, 43-45. 
Fait G., Nicelli M., Fragoulis G., Trevisan M., Capri E. (2007) Reduction of point sources of pesticide from a vineyard farm, Environ. Technol., in press.

Laine M., Jorgensen K. (1996) Straw compost and bioremediated soil as inocula for the bioremediation of chlorophenol-contaminated soil, Appl. Environ. Microb. 62, 1507-1513.

Martinez-Toledo M.V., Salmeron V., Gonzalez-Lopez J. (1992) Effect of the insecticides methylpyrimifos and chlorpyrifos on soil microflora in an agricultural loam, Plant Soil 147, 25-30.

Pizzul L., Castillo M.d.P., Stenström J. (2006a) Characterization of selected actinomycetes degrading polyaromatic hydrocarbons in liquid culture and spiked soil, World J. Microb. Biot. 22, 745-752.

Pizzul L., Castillo M.d.P., Stenström J. (2006b) Effect of rapeseed oil on the degradation of PAH in soil by Rhodococcus wratislaviensis, In revision with International Biodeterioration \& Biodegradation.

Racke K.D., Coats J.R., Titus K.R. (1988) Degradation of chlorpyrifos and its hydrolysis product, 3,5,6-trichloro-2-pyridinol, in soil, J. Environ. Sci. Heal. B 23, 527-539.

Rose S.C., Basford W.D., Carter A.D. (2003) On-farm bioremediation system to limit point source pesticide pollution, Proceeding of XII International Symposium on Pesticide Chemistry, Piacenza, Italy, June 2003, pp. 559-566.
Screpanti C., Accinelli C., Vicari A., Catizone P. (2005) Glyphosate and glufosinate-ammonium runoff from a corn-growing area in Italy, Agron. Sustain. Dev. 25, 407-412.

Sparling G.P., West A.W. (1988) A direct extraction method to estimate soil microbial-C - Calibration insitu using microbial respiration and C-14-labeled cells, Soil Biol. Biochem. 20, 337-343.

Torstensson L. (2000) Experiences of biobeds in practical use in Sweden, Pestic. Outlook 11, 169-212.

Torstensson L., Castillo M.d.P. (1997) Use of biobeds in Sweden to minimize environmental spillages from agricultural spraying equipment, Pestic. Outlook 8, 24-27.

Vischetti C., Capri E., Trevisan M., Casucci C., Perucci P. (2004) Biomassbed: a biological system to reduce pesticide point contamination at farm level, Chemosphere 55, 823-828.

Vischetti C., Perucci P., Casucci C., Monaci E., Dumontet S. (2006) Biochemical parameter changes in urban-waste compost used as biofilter for pesticide decontamination, Int. J. Environ. An. Ch. 86, 195-205.

von Wirén-Lehr S., Castillo M.d.P., Torstensson L., Scheunert I. (2001) Degradation of isoproturon in biobeds, Biol. Fert. Soils 33, 535-540. 